Article

\title{
Horizontal Bending Angle Optimization Method for Scraper Conveyor Based on Improved Bat Algorithm
}

\author{
Ting Liu ${ }^{1}$, Chao Tan ${ }^{1, *}$, Zhongbin Wang ${ }^{1}$, Jing $X u^{2}$, Yiqiao Man ${ }^{1}$ and Tuo Wang ${ }^{3}$ \\ 1 School of Mechatronic Engineering, China University of Mining \& Technology, Xuzhou 221116, China; \\ Liuting_cumt@126.com (T.L.); wangzb@cumt.edu.cn (Z.W.); manyiqiao@163.com (Y.M.) \\ 2 Marine Equipment and Technology Institute, Jiangsu University of Science and Technology, \\ Zhenjiang 212003, China; xujingcmee@cumt.edu.cn \\ 3 State Key Laboratory for Geomechanics and Deep Underground Engineering, School of Mechanics and Civil \\ Engineering, China University of Mining and Technology, Xuzhou 221116, China; twang1089@126.com \\ * Correspondence: Tanchao_cumt@126.com; Tel.: +86-516-8388-4512
}

Received: 4 March 2019; Accepted: 15 April 2019; Published: 22 April 2019

\begin{abstract}
The horizontal bending angle of scraper conveyor has a great influence on the running resistance, the current consumption, coal winning efficiency of the working surface, etc. Approximately $1-3^{\circ}$ is usually the range of horizontal bending angle, but does not indicate the optimum bending angle of the coal mining face. To find the optimal horizontal bending angle, an optimization method is proposed. A mathematical calculation model of the running resistance of the scraper is established based on the direction of the shearer operation. Then, a method of adjusting the step size of the search by inertia weight and expanding fly distance range obeying the $t$-distribution is proposed based on the basic bat algorithm (BA). Finally, an industrial application was conducted in 21220 Changcun fully mechanized coal mining face, Henan Province. The results show that the current consumption by the scraper conveyor was reduced by $31 \%$ when the horizontal bending angle of the S-bending area was $0.66^{\circ}$. Meanwhile, the theoretical current has good consistency with the experimental data, and the average absolute error was $3 \%$.
\end{abstract}

Keywords: scraper conveyor; S-bending area; horizontal bending angle; improved bat algorithm; inertia weight; t-distribution

\section{Introduction}

The scraper conveyor is one of the key equipment for underground coal mining [1]. It not only transports coal, but also provides the running track of the shearer and the positioning of the hydraulic support. It is the connection point of the fully mechanized mining equipment [2,3]. In the fully mechanized mining face, the middle slot of the scraper conveyor is pushed by the hydraulic support to the coal wall by a step (the length of the step is usually $600-1000 \mathrm{~mm}$ ), which is pushed to the next cutting plane. At the same time, the adjacent middle grooves will be driven by each other and rotated to form a transition section. To ensure the stable operation of the scraper conveyor, the transition section will form two anti-symmetrical bending lines. This horizontal bending section presents an $\mathrm{S}$ shape, hence it is called the S-bending area [4]. The angle between the adjacent middle grooves of the S-bending area of the scraper conveyor is called the horizontal bending angle. The horizontal bending angle of the S-bending area of the scraper conveyor is selected from $1^{\circ}$ to $3^{\circ}$, and the horizontal bending angle used under the mine is usually determined empirically. 
Previous research on scraper conveyor has mainly focuses on the monitoring [5,6] and calculation [7-9] of running load, dynamical problems [10-12], friction and wear [13-15]. However, studies rarely account for the effect of the horizontal bending angle of the S-bending area on the additional resistance, the running load, the production energy consumption ratio, the mean time between failures (MTBF) of the mining equipment and the shear cutting efficiency has been rarely investigated. In fact, if the horizontal bending angle of the S-bending area is improperly selected, the additional resistance will increase [16], the middle groove and the sprocket assembly will be seriously worn [17], the current fluctuation is large, the energy consumption of the mining equipment is high, the equipment service life is low and the MTBF is small.

Bat Algorithm (BA) was proposed by Yang in 2010 based on swarm intelligence $[18,19]$. It simulates bat behavior, which avoids obstacles, detects preys and locates the roosting crevices in the dark. Based on the bionic principle, BA simulates the optimization and search process with a population bat individual movement processes and searches for the prey [20,21]. BA has the advantages of simple structure, few parameters, strong robustness, and is easy to understand and implement. Since the BA was proposed, it has been widely applied in construction machinery [22], finances [23], forecasting [24], etc. However, similar to other optimization algorithms, the basic BA also has the disadvantage of falling into local optimum.

Considering the above observations, a method based on improved BA (MBA) for optimizing horizontal bending angle is proposed. The rest of this paper is organized as follows. In Section 2, the basic theory of the mathematical models of the running resistance of scraper conveyor and BA are described. Then, the MBA and the whole flow of proposed horizontal bending angle optimization scheme are illustrated in Section 3. Some simulations and analysis according to the actual working conditions of the fully mechanized mining face are presented in Section 4 to validate the superiority of the proposed method. In Section 5, a mine application is presented to validate the practical effect. In Section 6, some conclusions and outlooks are summarized.

\section{Basic Theory}

\subsection{Analyze the Running Resistance of the Scraper Conveyor}

The running resistance of scraper conveyor is related to the amount of coal carried and the running direction of the shearer. Its running resistance is divided into the running resistance of the straight section and the additional resistance of the S-bending section.

Straight line running resistance

Previous calculation of the running resistance did not take into account the actual transport state of scraper conveyor $[25,26]$. According to the actual working conditions, the middle slot of the scraper conveyor is divided into two parts innovatively, the heavy-duty section and no-load section. Combining with the cutting technology of the shearer, the calculation method of the operating resistance of the scraper conveyor is shown as follows:

$$
W_{(m, d)}= \begin{cases}\left(q \mu_{s s}+q_{0} \mu_{c s}\right) g L_{m} \cos \theta \pm\left(q+q_{0}\right) g L_{m} \sin \theta+q_{0} g\left(\mu_{c s} \cos \theta \mp \sin \theta\right)\left(L-L_{m}\right) & d=1 \\ q_{0} g\left(\mu_{c s} \cos \theta \mp \sin \theta\right) L & d=2\end{cases}
$$

where $q$ is the linear density of the heavy-duty part of the scraper conveyor, $\mathrm{kg} / \mathrm{m} ; q_{0}$ is the load weight per unit length of the scraper chain, $\mathrm{kg} / \mathrm{m}$; $\mu_{s s}$ is the resistance coefficient of the load in the chute; $\mu_{c s}$ is the scraper chain movement resistance coefficient in the chute; $L$ is the total length of the scraper conveyor, $\mathrm{m}$; and $\theta$ is the vertical bending angle of the scraper conveyor, ${ }^{\circ}$; The length of the heavy-duty section $L_{1}=x_{0}+v_{s} t_{s}$, and the no-load length $L_{2}=L-L_{1}, \mathrm{~m} ; v_{s}$ is the speed of the shearer, $\mathrm{m} / \mathrm{min} ; t_{s}$ is the shearer operating time, $\mathrm{s} ; x_{0}$ is the distance from the starting point of the scraper conveyor to the head, $\mathrm{m} ; m=1$ when the shearer and scraper conveyor are running in opposite 
directions. Otherwise, $m=2 ; d=1$ indicates the resistance of the upper chain of the middle slot, and $d=2$ indicates the resistance of the lower chain of the middle slot.

S-bending section additional resistance

Due to the angle between the adjacent middle slot of the S-bending area, the squeegee chain can be regarded as a flexible body sliding around the fixed circular ring guide when sliding therein [27-30]. The additional resistance $\left(\Delta F_{m}\right)$ of the S-bending area includes the additional traction resistance of the chain and the squeezing force of the squeegee striking the middle trough. The expression of $\Delta F_{m}$ is expressed as follows:

$$
\Delta F_{m}=\sum_{s}^{K} r \cdot F_{s m}+F_{d}\left(e^{(K+1) \mu \alpha^{\prime}}-1\right)+C_{d}\left(\frac{e^{\mu \alpha^{\prime}}\left(e^{K \mu \alpha^{\prime}}-1\right)}{e^{\mu \alpha^{\prime}}-1}-K\right) \quad(d=1,2 ; m=1,2)
$$

where $K$ is the total number of horizontal curved chutes; $r$ is the lateral friction coefficient of the squeegee and the middle slot; $F_{d}$ is the chain tension in the end of the chute before the horizontal bending section, $\mathrm{N} ; \alpha^{\prime}$ is the angle between adjacent middle slots, ${ }^{\circ} ; \mu$ is the friction coefficient value of the scraper chain and the chute; the resistance of each middle slot is $C_{1}=l\left(q+q_{0}\right)\left(\mu_{s s} \cos \theta \pm \sin \theta\right), C_{2}=$ $q_{0}\left(\mu_{c s} \cos \theta \mp \sin \theta\right) ; l$ is the length of a middle slot, $\mathrm{m} ; F_{s m}$ is the lateral pressing force [28].

\subsection{Bat Algorithm}

Bat Algorithm (BA) is a heuristic search algorithm, which was proposed by Yang in 2010. By simulating the bat foraging behavior, local and global optimality can be obtained through appropriate iteration. The bat algorithm search process is as follows:

Step 1.1: Parameter initialization. $P$ is the initial bat population size. The maximum number of iterations is $N$. The pulse frequency is in the range $\left[f_{\min }, f_{\max }\right] . r_{i}^{0}$ is the pulse rate. $A$ is the maximum pulse sound intensity. The sound intensity attenuation coefficient is $\alpha$. The frequency increase coefficient is $\gamma$. D is the dimension of the search variable.

Step 1.2: Population initialization. Randomly initialize the position of the bat individual $x_{i}(i=1$, $2, \ldots, D)$ within the search range. Find the best bat position $x^{*}$ in the current search. Calculate the fitness value $f\left(x_{i}\right)$ of each bat, and find out the best location and fitness value of the current bat.

Step 1.3: Movement speed and position update. Let the bats search in the $D$-dimensional space, the position and velocity of the bat $i$ are $x_{i}^{t-1}$ and $v_{i}{ }^{t-1}$ at $(t-1)$ time. The current global optimal position is $x^{*}$. For bat $i$ at time $t$, its position $x_{i}^{t}$ and speed $v_{i}{ }^{t}$ update formula are given by:

$$
\left\{\begin{array}{l}
f_{i}=f_{\min }+\left(f_{\max }-f_{\min }\right) \beta \\
v_{i}^{t}=v_{i}^{t-1}+\left(x_{i}^{t-1}-x^{*}\right) f_{i} \\
x_{i}^{t}=x_{i}^{t-1}+v_{i}^{t}
\end{array}\right.
$$

where $\beta \in[0,1]$ is a random vector drawn from a uniform distribution.

Step 1.4: Local search. Each bat randomly selects one from the current optimal solution, and its new solution is generated by random walks. The formula is shown as follows:

$$
x_{\text {new }}=x_{\text {old }}+\varepsilon A^{t}
$$

where $\varepsilon \in[0,1]$ is the random number, while $A^{t}=\left\langle A^{t}{ }_{i}>\right.$ is the average loudness of all the bats at this time step. 
Step 1.5: Pulse emission loudness and emission frequency update. First, a new random number is generated within $[0,1]$, and then the size relationship between the current bat and the new bat adaptation is compared. New bats are accepted if the following conditions are met. The adjustment formula of the ultrasonic loudness $A_{i}$ and the pulse rate $r_{i}$ is:

$$
\begin{gathered}
A_{i}^{t+1}=\alpha A_{i}^{t} \\
r_{i}^{t+1}=r^{0}(1-\exp (-\gamma t))
\end{gathered}
$$

where $\alpha$ and $\gamma$ are constants.

Step 1.6: Global optimal evaluation. Calculate the fitness of all individuals in the current population, and record the optimal bat position and its fitness value.

Step 1.7: Iteration termination. If the current iteration number $t$ reaches the maximum number of iterations $N$, the iteration is stopped, otherwise, repeated Steps 1.3-1.6. The iteration process is presented in Figure 1.

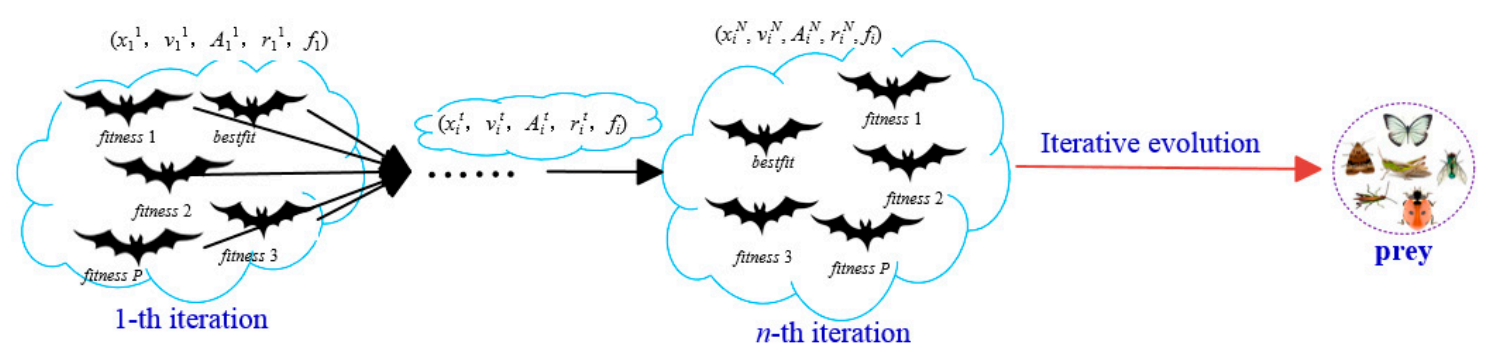

Figure 1. Foraging process of the bat.

\section{The Proposed Method}

\subsection{Improvement of $B A$}

Bat algorithm has the advantages of simple structure, few parameters, strong robustness and easy implementation. However, the bat algorithm has problems such as slow convergence and easily falling into local optimum.

To improve the convergence speed of the bat algorithm, this paper uses the inertia weight $(\omega(\mathrm{t}))$ method to adjust the step size of the bat flight. The $\omega(\mathrm{t})$ coefficient distribution diagram is shown in Figure 2. The inertia weight function is shown in Equation (7). The speed update formula of the bat search is described in Equation (8).

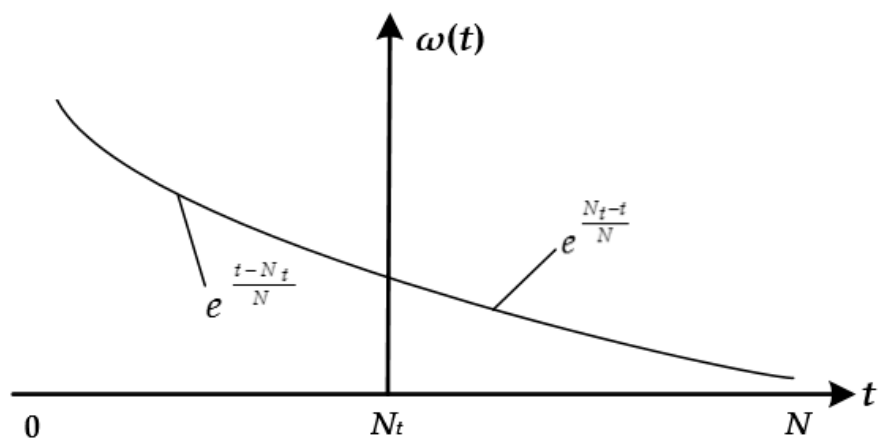

Figure 2. Distribution of inertia weight coefficient. 


$$
\omega(t)=\exp \left(-\left|\frac{t-N_{t}}{N}\right|\right)= \begin{cases}\exp \left(\frac{t-N_{t}}{N}\right) & 0<t \leq N_{t} \\ \exp \left(\frac{N_{t}-t}{N}\right) & N_{t}<t \leq N\end{cases}
$$

where $t$ is the number of iterations of the bat; $N$ is the maximum number of iterations of the bat algorithm; and $N_{t}$ is the iterative demarcation point, it can be determined by the actual work in the field.

$$
v_{i}^{t}=\left(x_{i}^{t-1}-x^{*}\right) f_{i}+v_{i}^{t-1} \cdot \omega(t)
$$

To solve the problem of falling into local optimum, this paper expands the range of bat fly distance range $(F R)$ obeying the $\mathrm{t}$-distribution. The shape of the curve of the $\mathrm{t}$-distribution is related to the degree of freedom ( $\mathrm{df}$ ). When $\mathrm{df}=1$, the $\mathrm{t}$-distribution curve coincides with the Cauchy distribution curve. When $\mathrm{df} \rightarrow \infty$, the $\mathrm{t}$-distribution is normally distributed. The probability density function curves of Cauchy distribution, t-distribution, and normal distribution are shown in Figure 3. The rules for random migration of bat populations is expressed as:

$$
x_{i}^{t}=x_{i}^{t-1}+v_{i}^{t}+F R
$$

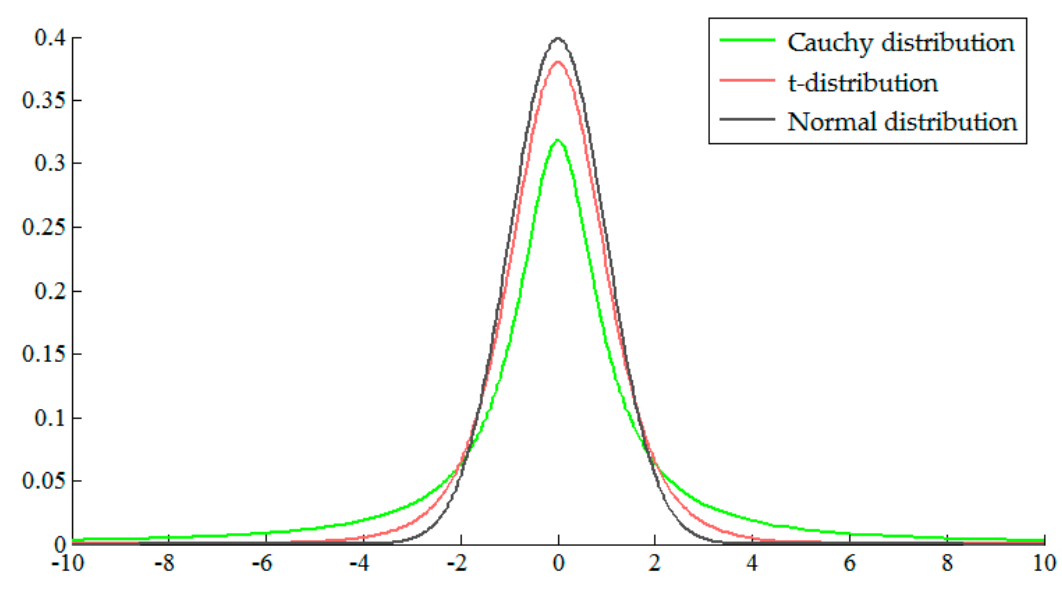

Figure 3. Probability density function curve of Cauchy distribution, t-distribution and Normal distribution.

The Cauchy distribution has a good global development capability, while the Normal distribution has a stable local search capability. The number of iterations of the bat population is taken as the $\mathrm{df}$ of the $t$-distribution. As the number of iterations increases, the $F R$ varies between the Cauchy distribution and the Normal distribution. At the beginning of the bat population iteration, the t-distribution is close to the Cauchy distribution. At this time, the bat search flight range and population diversity are improved, so that the local optimum is avoided. In the late stage of the bat population iteration, the $\mathrm{t}$-distribution is close to the Normal distribution. In this process, the bat's local search ability is strong and the convergence speed is fast.

\subsection{Design of the Fitness Function}

Since the evaluation index value is a dimensional expression, this paper uses linear normalization to transform it into a scalar expression. Considering the three-machine work of the fully mechanized mining face, the running load of the scraper conveyor $\left(p_{m 1}\right)$, the support requirements of the hydraulic support $\left(p_{m 2}\right)$ and the efficiency of the shearer chamfering feed $\left(p_{m 3}\right)$ are used as evaluation indicators $\left(p_{m j}\right)$. The calculation formulas for the evaluation indicators $p_{m 1}, p_{m 2}$ and $p_{m 3}$ are as follows: 


$$
\begin{gathered}
p_{m 1}=W_{(m, d)}+\Delta F_{m} \\
p_{m 2}=K \\
p_{m 3}=\frac{L_{k p} / t_{c f}}{L / t_{c d}}
\end{gathered}
$$

where, $L_{k p}$ is the length of the S-bending area, $\mathrm{m}[31] ; t_{c f}$ is the time for the shearer chamfering feed, $\mathrm{s}$; and $t_{c d}$ is the total time used by the shearer to cut a piece of coal, $\mathrm{s}$.

The first and second quadrants of the unit circle are used as the scoring system, which is not only easy to calculate, but also has increasing and decreasing trends. The evaluation score formula is calculated as follows:

$$
S_{m j}=100 \cdot\left(1-p_{m j}^{2}\right)^{\frac{1}{2}}
$$

where $S_{m j}$ is the score of the $j$-th index of the known shearer running direction, $j$ is the index number, $j=$ $1,2,3$; and $p_{m j}$ is the evaluation index of the corresponding $S_{m j}$. The score of the whole working mode can be obtained from each evaluation score, and the total score function $S_{\text {score }}$ is shown as follows:

$$
S_{\text {score }}=\sum_{m}^{2} \sum_{j}^{3} a_{m j} S_{m j}
$$

where $a_{m j}$ is the weight coefficient, and its size is determined by tomographic analysis [32].

The additional resistance $\Delta F_{m}$ of the scraper conveyor, the number of the slot $(K)$ in the S-bending area and the length $\left(L_{k p}\right)$ of the S-bending area are all related to the horizontal bending angle $\alpha^{\prime}$. Therefore, the fitness function is created with $\alpha^{\prime}$ as the objective of optimization. The higher is the score of the objective function for $\alpha^{\prime}$, the better is the working mode of the three-machine collaboration. $S_{\text {score }}$ is used as the fitness function of the MBA to iteratively optimize.

$$
\text { function } S_{\text {score }}=\operatorname{Fun}\left(\alpha^{\prime}\right)
$$

\subsection{Flowchart of Optimization Method for Horizontal Bending Angle}

Based on the above analysis, an innovative method based on the improved bat algorithm (MBA) to optimize the horizontal bending angle of the S-bending area of the scraper conveyor is proposed. The flowchart for optimizing horizontal bending angle of S-bending area based on MBA is shown in Figure 4. The optimization steps are summarized as follows:

Step 2.1: Collect information. Extracting and processing parameter information of fully mechanized mining face.

Step 2.2: Initialize the parameters of the MBA optimization algorithm and set the number of iterations for the population.

Step 2.3: Population initialization. Each position of the bat is considered as a horizontal bending angle value, and the fitness value of each bat is the evaluation value of the working surface.

Step 2.4: Movement speed and position update. The update of the speed and position of each generation of bat population can be obtained according to Equations (8) and (9).

Step 2.5: Termination condition. When the iteration number $t$ reaches the maximum $\mathrm{N}$, the iteration is stopped, and then the highest score and its corresponding optimal $\alpha^{\prime}$ value are output; otherwise, Steps 2.2-2.4 are repeated. 


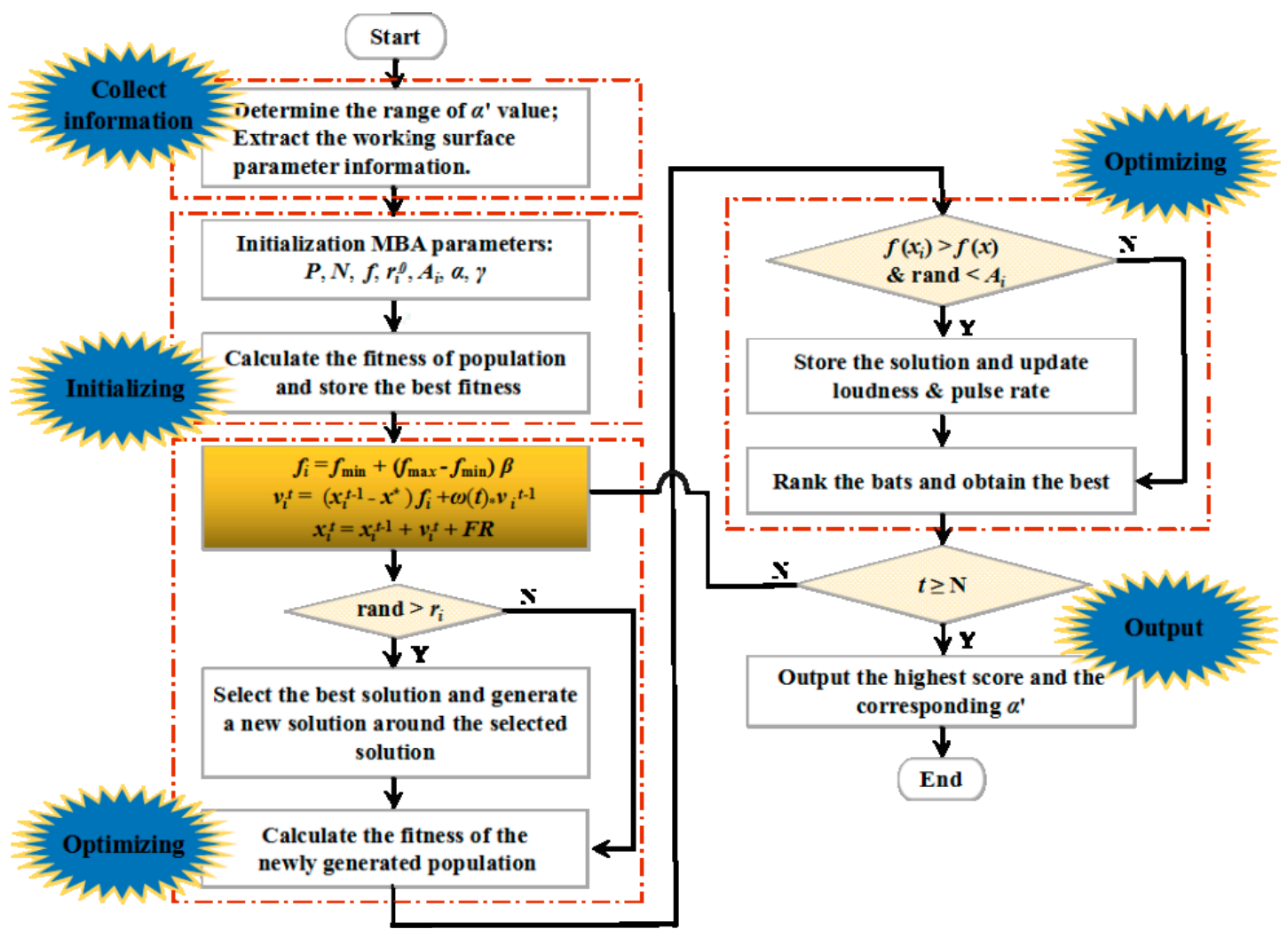

Figure 4. The flowchart for optimizing horizontal bending angle of S-bending area based on MBA.

\section{Simulation and Analysis}

To validate the superiority of the proposed method, the established fitness function was substituted into iterative optimization. Then, the original BA (BAO), the bat algorithm based on bacterial algorithm (BCBA) [33] and a globally optimized adaptive BAT memory algorithm (ABAM) [34] and the proposed MBA were compared. Maximum score value $\left(S_{\text {score_max }}\right)$, the mean value of the horizontal bending angle value (Mean) and the standard deviation (SD) were regarded as evaluation criteria for the four optimization algorithms. Finally, compare the optimization effects of the four algorithms were compared. The configuration of the computer used is shown in Table 1.

Table 1. Computer Configuration.

\begin{tabular}{cc}
\hline Operating System & Windows 7 (64 bits) \\
\hline CPU & Intel(R) i5-4590 (4 cores, 3.3 GHz) \\
Memory & $8 \mathrm{~GB}(\mathrm{DDR} 3)$ \\
Matlab version & 8.3 \\
Hard disk space & SSD $(465 \mathrm{~GB})$ \\
\hline
\end{tabular}

\subsection{Parameter Information Acquisition}

All parameter information of working face was acquired from the 21220 fully mechanized mining face of Changcun Mine of Henan Da You Energy Co., Ltd. (Sanmenxia, China). Coal mining face and equipment parameters are shown in Table 2. 
Table 2. Coal mining face and equipment parameters.

\begin{tabular}{ccc}
\hline Object & Technical Parameters & Value \\
\hline Working face & Length $(\mathrm{m})$ & 270 \\
\hline Shearer & Height $(\mathrm{m})$ & 2 \\
(MG300/730-WD2) & Cut depth $(\mathrm{m})$ & 0.63 \\
& Haulage speed $(\mathrm{m} / \mathrm{min})$ & 4.5 \\
\hline & Chain speed $(\mathrm{m} / \mathrm{s})$ & 1.31 \\
Scraper conveyor & Motor & 1500 \\
(SGZ800/800) & Transportation volume $(\mathrm{t} / \mathrm{h})$ & $1503 \times 800 \times 308$ \\
& Middle slot $(\mathrm{mm})$ & 1008 \\
\hline
\end{tabular}

\subsection{Horizontal Bending Angle Optimization Effect Analysis}

In the actual working condition of the mine, the S-bending area of the scraper conveyor, also called transition section, is formed by the hydraulic support pushing the middle groove to the next cutting plane. For the unmined cutting face, shearer cutting coal rock usually starts chamfering in the S-bending area. Therefore, the horizontal bending angle of the S-bending area has an important influence on the production of working face and the chamfering feed of the shearer.

The fitness function was established in combination with the actual working conditions under the mine. The higher was the evaluation score, the higher was the production efficiency of the working face. The parameter information of the working face was inputted into the fitness function. Then, the four algorithms of ABAM, BCBA, BAO and MBA were used to iteratively search for the highest score $\left(S_{\text {score-max }}\right)$ and the corresponding optimal $\alpha^{\prime}$. Compare the paths searched by 4 different algorithms 3 times, and the comparison results are shown in Figure 5.

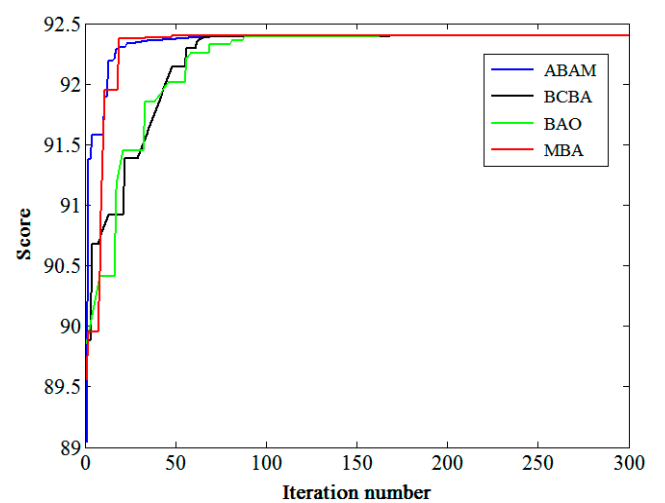

(a)

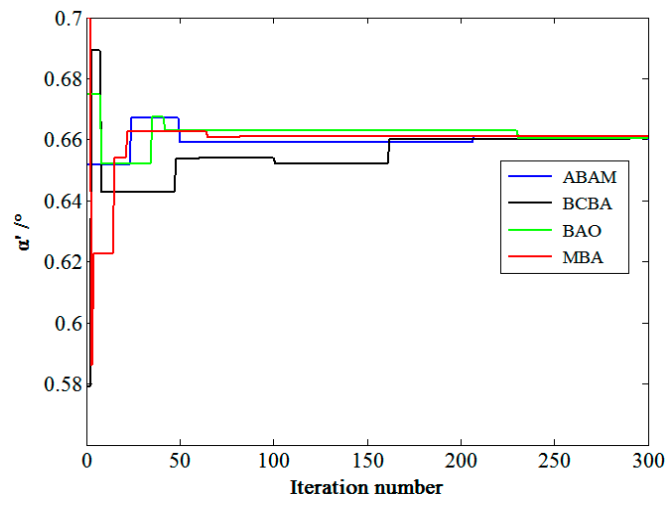

(b)

(1) the path of four different algorithms iterative search.

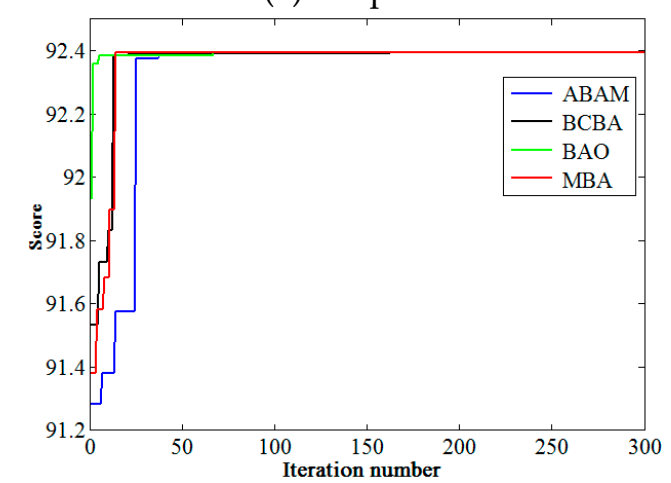

(a)

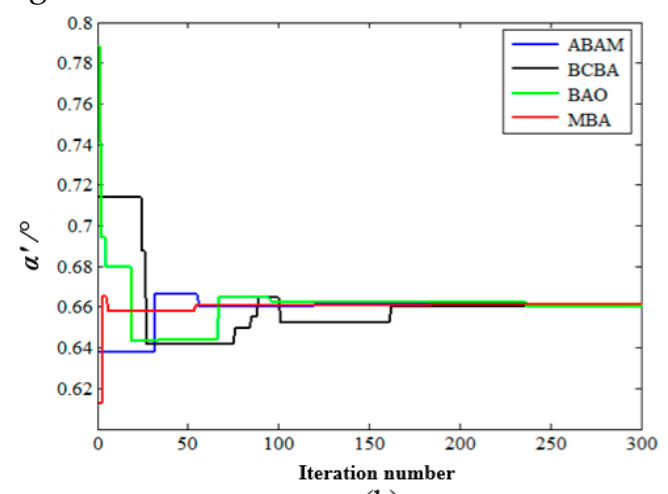

(b)

(2) the path of four different algorithms iterative search.

Figure 5. Cont. 


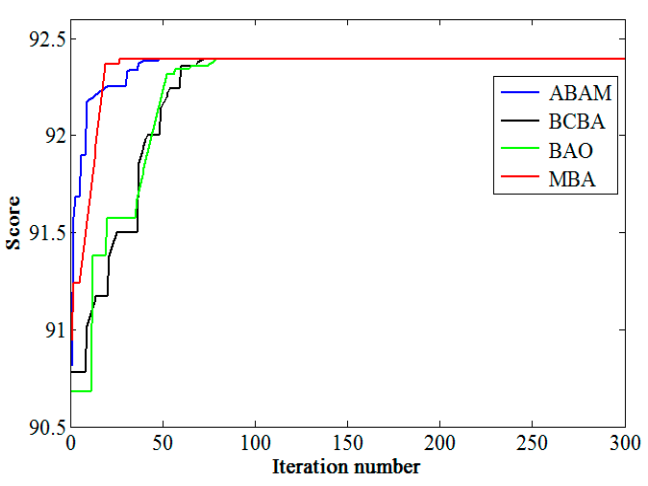

(a)

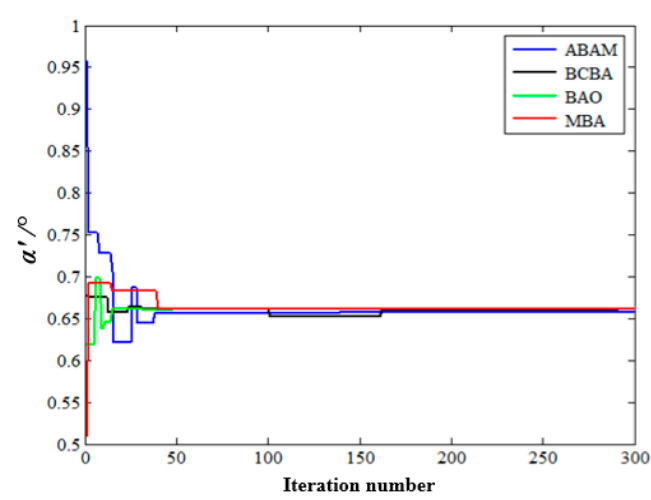

(b)

(3) the path of four different algorithms iterative search.

Figure 5. Comparison of optimization results of four different optimization algorithms.

As shown in Figure 5, the four optimization algorithms were iterated 300 times, and the evaluation score of the search was small, about 92.4 points. In the process of searching, the MBA algorithm reached the optimal value by 40 iterations, while the ABAM and BCBA needed 70 iterations, and the BAO needed 90 iterations, as shown in Figure $5 \mathrm{a}$. when $\alpha^{\prime}$ reached the optimum value of $0.66^{\circ}$, the MBA had iterated 40 times, while the BAO 100 times. The ABAM and BCBA algorithm search process oscillated very sharply, and began to stabilize in the 150th generation, as shown in Figure 5b.

To improve the production efficiency of the working face when the shearer bevel cutting, this study combined the running direction of the shearer and optimized the $\alpha^{\prime}$ of the S-bending area by using the proposed method and three other algorithms. The optimization results are shown in Figure 6.

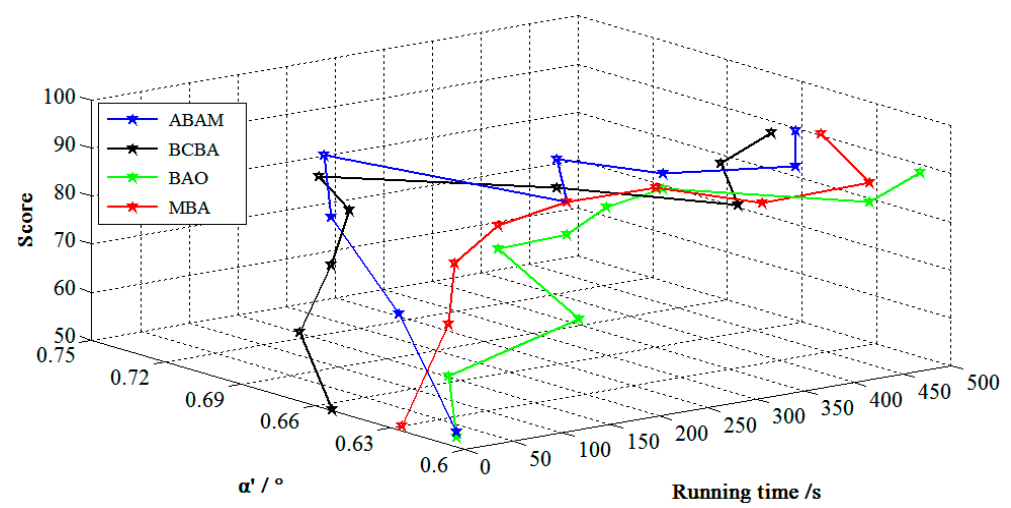

(a) $m=1$

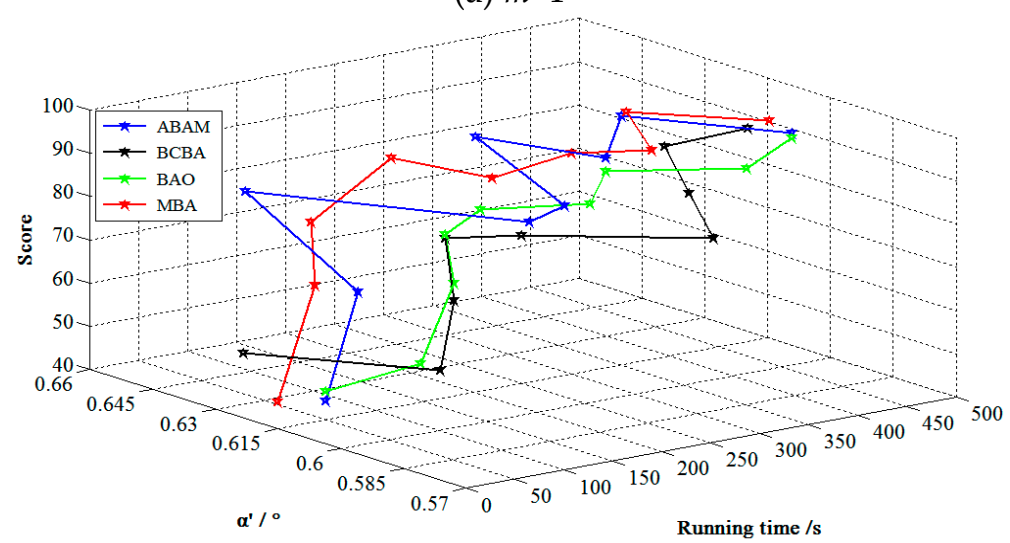

(b) $m=2$

Figure 6. Optimal horizontal bending angle and corresponding score distribution map. 
As shown in Figure 6, in the shearer bevel cutting stage, the horizontal bending angle $\alpha^{\prime}$ of the S-bending area was $\left[0.60^{\circ}, 0.75^{\circ}\right],\left[0.57^{\circ}, 0.66^{\circ}\right]$. The optimal horizontal bending angle was not linear with the cutting time. Because the mine environment is complex and variable, the value of the $\alpha^{\prime}$ was different when the shearer cuts forward and reverses. In the shearer cutting process, the working surface evaluation score increased from 50 points to 92.4 points.

\subsection{Comparison and Discussion}

To analyze the superiority of the proposed method, the maximum score $\left(S_{\text {score_max }}\right)$, the mean value (Mean) and the standard deviation (SD) of the four algorithms were compared. The performance comparison results of the four different algorithms are shown in Table 3. As can be seen in the table, the $S_{\text {score_max }}$ of MBA, ABAM, BCBA and BAO was between 92.394 and 92.396. The mean of the MBA optimized $\alpha^{\prime}$ was $0.66^{\circ}$. The mean values of ABAM, BCBA and BAO optimized $\alpha^{\prime}$ were $0.659^{\circ}, 0.656^{\circ}$, $0.655^{\circ}$, respectively. The errors of the means were $0.6 \%, 0.77 \%, 1.5 \%$, and $3.4 \%$, respectively. The SDs of MBA, ABAM, BCBA and BAO were $1 \%, 2.1 \%, 2.5 \%$, and $2.8 \%$, respectively. Overall, the proposed MBA optimization algorithm converged quickly and with a small deviation.

Table 3. The performance comparison results of the four different algorithms.

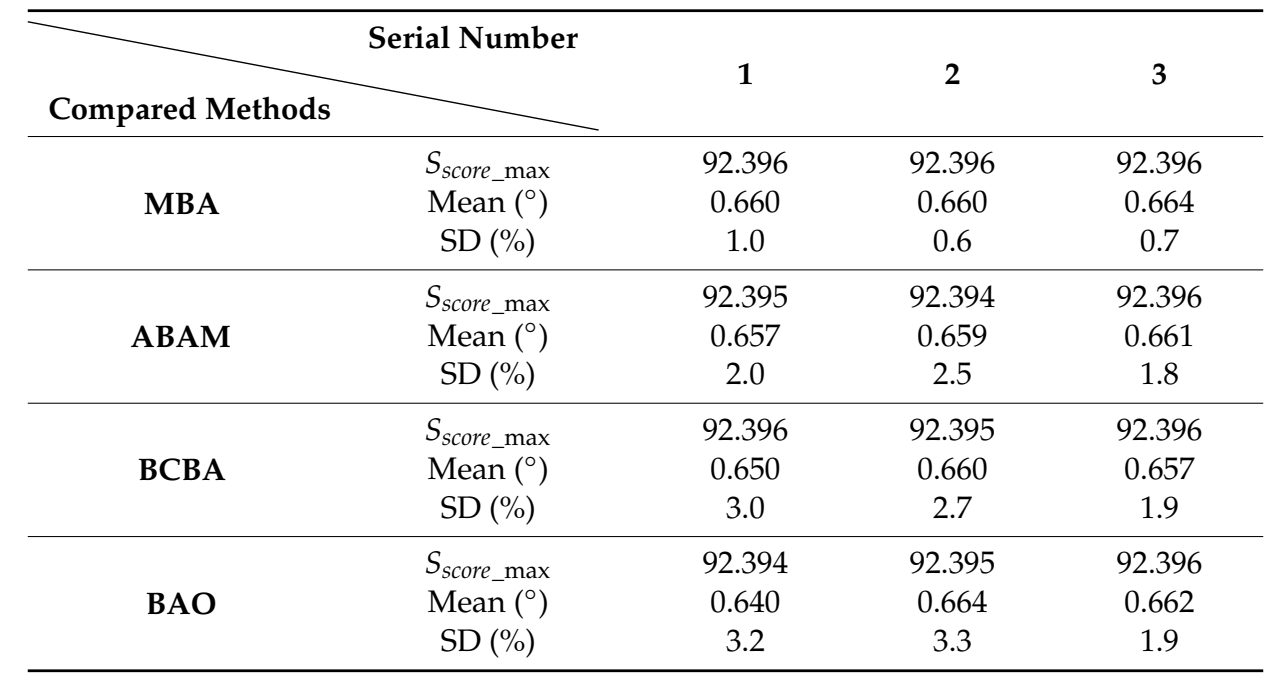

\section{Experiment and Application}

The horizontal bend angle optimization system for the S-bending area of the scraper conveyor based on the proposed method was experimentally applied to the fully mechanized mining face, as shown in Figure 7. The application was tested at the 21220 working face of Changcun Mine of Henan Da You Energy Co., Ltd. Since the current of the scraper conveyor can intuitively reflect the load [35], combined with the relationship between the $\alpha^{\prime}$ and the load analyzed in Section 2.1, the optimal value of the $\alpha^{\prime}$ could be verified by collecting the current consumed by scraper conveyor. The current transformer was used to collect the current of the head and tail of the scraper conveyor, and the data were transmitted through the wireless MESH network installed on the hydraulic support. The ground monitoring center was used for remote monitoring and control. 


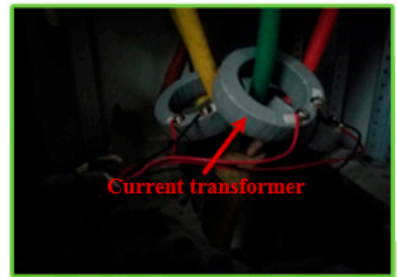

Data collection

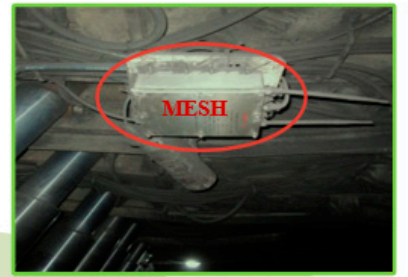

Data transmission

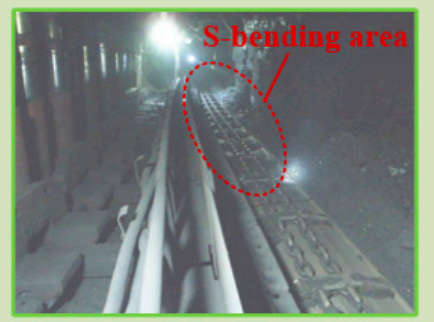

Coal mining working face

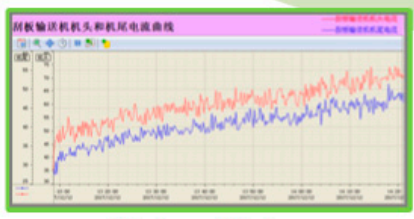

Data archiving

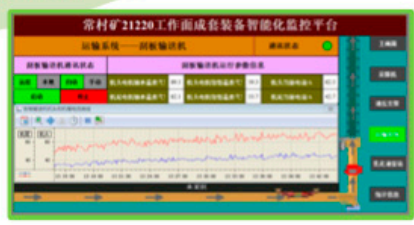

Monitoring interface

Figure 7. Industrial application of the proposed method.

Due to the environment under the mine is complicated and dangerous, the three angles of $0.5^{\circ}$, $0.66^{\circ}$ and $1.5^{\circ}$ were used for comparative experiments, where $1.5^{\circ}$ is the horizontal bending angle value commonly used for the working surface. $0.66^{\circ}$ is optimal horizontal bending angle obtained by the proposed method, and $0.5^{\circ}$ is used to check whether the smaller $\alpha^{\prime}$ is, the better the working condition is. To verify the correctness of the proposed method, the current data collected under mine were compared with the theory, and the comparison results are shown in Figures 8 and 9.
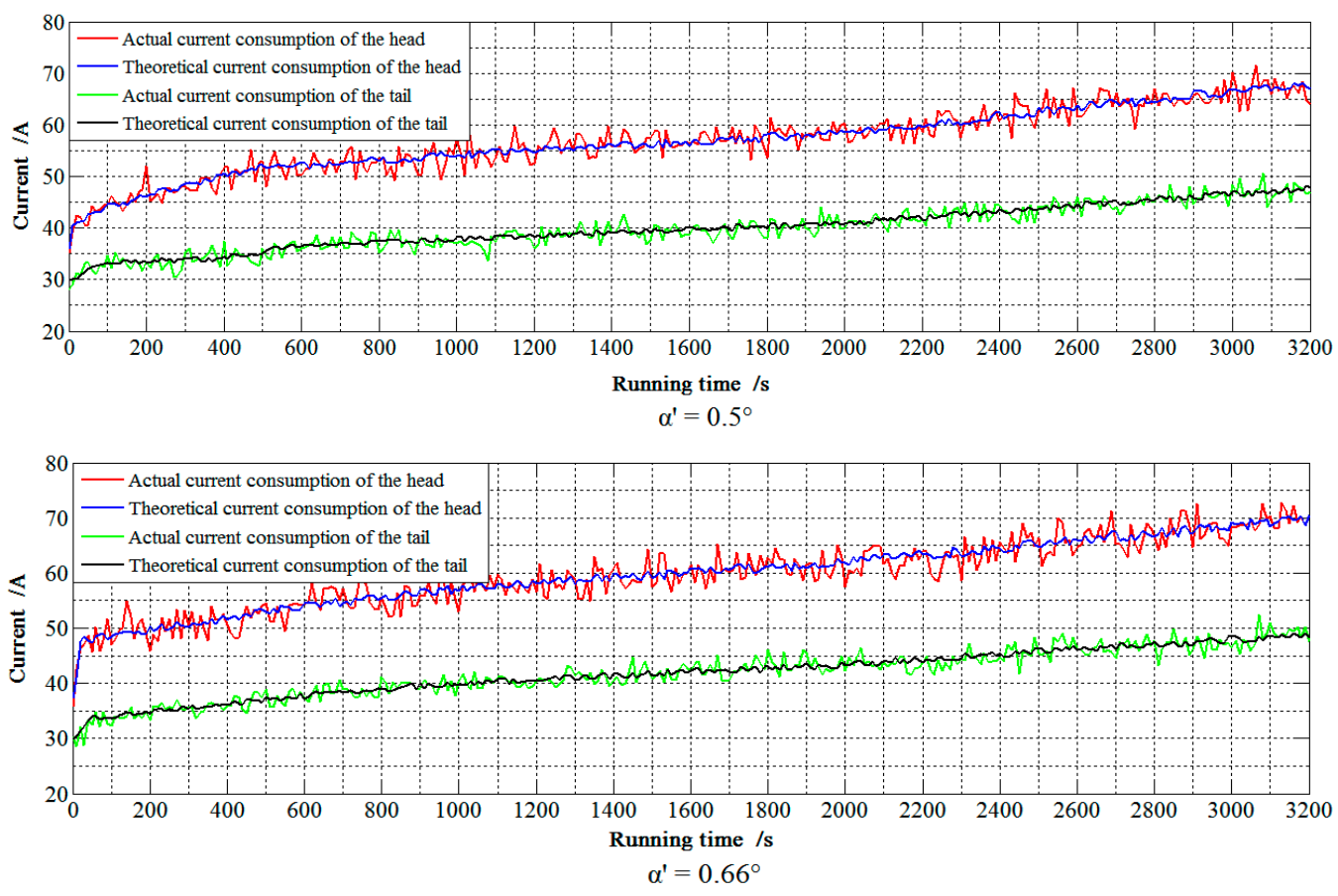

Figure 8. Cont. 


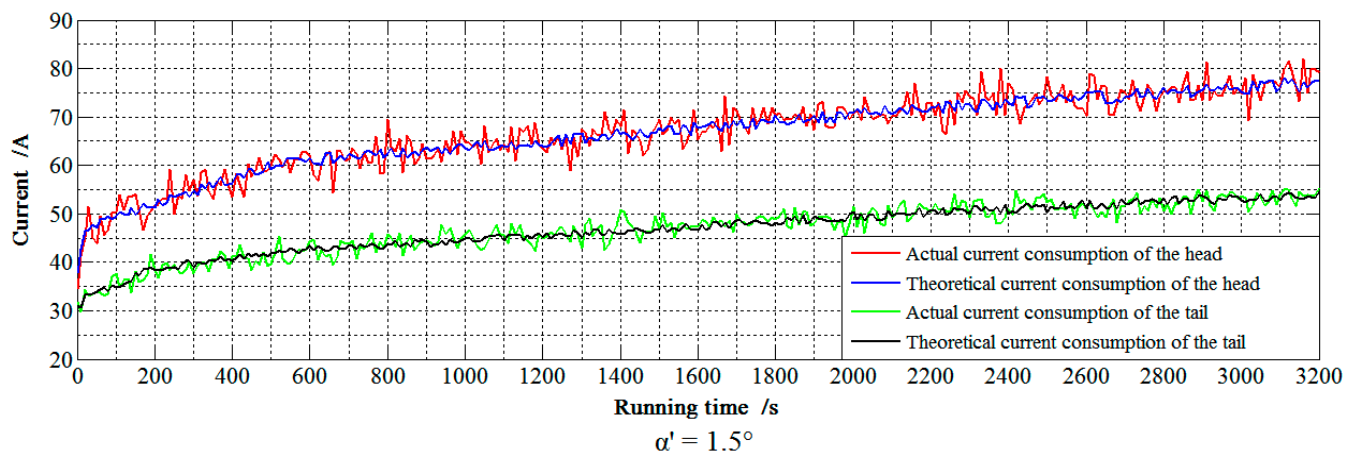

Figure 8. Comparison between the measured and theoretical current of scraper conveyor when $m=1$.
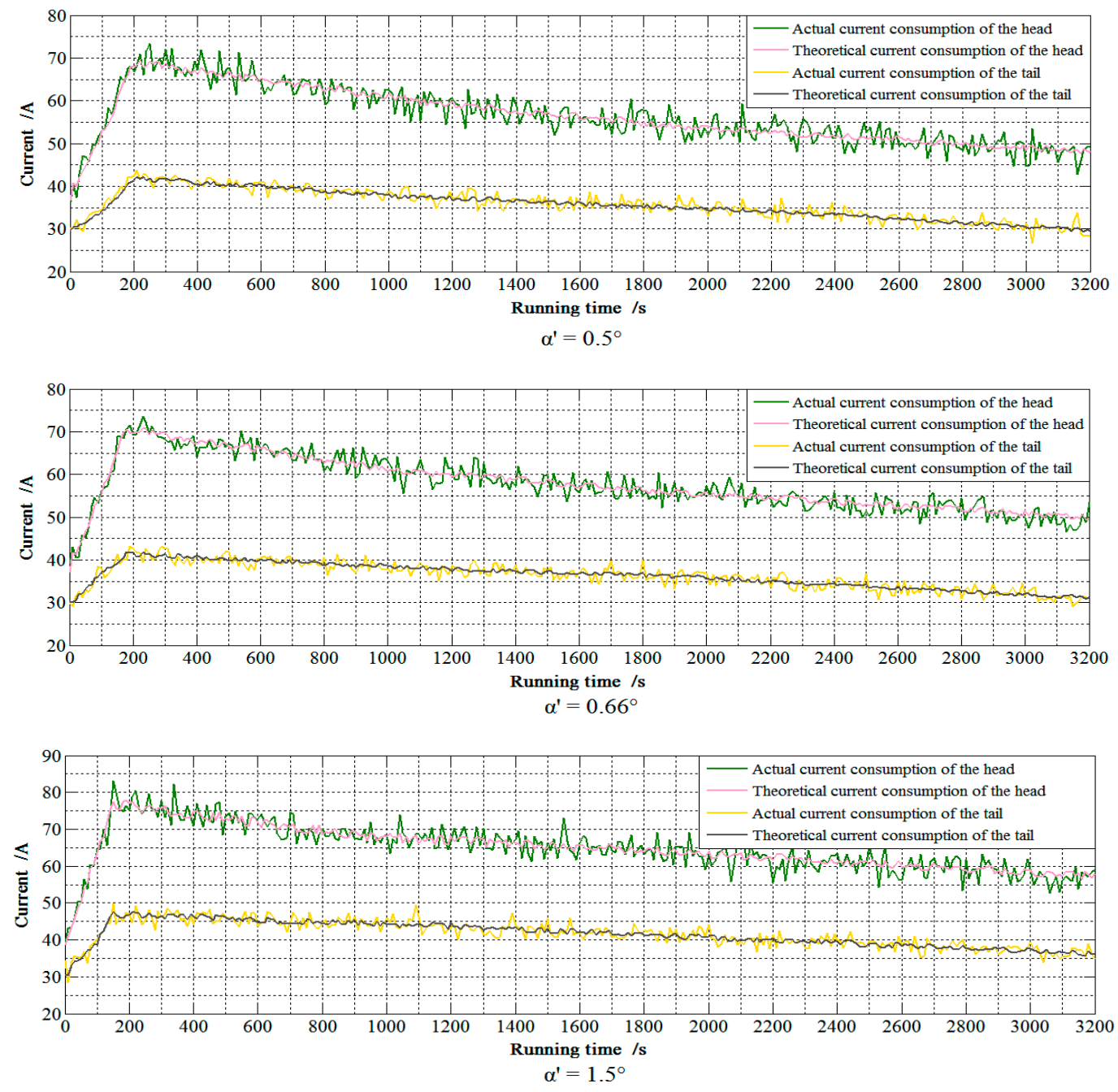

Figure 9. Comparison between the measured and theoretical current of scraper conveyor when $m=2$.

The current required by the scraper conveyor varied with the $\alpha^{\prime}$. When $\alpha^{\prime}=1.5^{\circ}$, the current consumption of the motor was about $7 \mathrm{~A}$ larger than that of $\alpha^{\prime}=0.5^{\circ}$ and $0.66^{\circ}$. When $\alpha^{\prime}=0.66^{\circ}$, the current consumption of the scraper conveyor drive motor was $2 \mathrm{~A}$ larger than $\alpha^{\prime}=0.5^{\circ}$. To verify the accuracy and practicality of the proposed method, the average absolute error was used. The average absolute error calculation results are shown in Table 4.

Under the three different $\alpha^{\prime}$, the maximum and minimum average absolute errors of the actual-theoretical current were $3.68 \%$ and $2.11 \%$, respectively. The average absolute error of $\alpha^{\prime}$ 
$=0.66^{\circ}$ was smaller than that of $\alpha^{\prime}=0.5^{\circ}$ and $1.5^{\circ}$. The error between the theoretical calculation and experimental data was very small, and the trend of increase and decrease was consistent.

Table 4. Actual vs. theoretical current average absolute error list at different $\alpha^{\prime}$.

\begin{tabular}{cccccccc}
\hline & $\alpha^{\prime}$ & \multicolumn{2}{c}{$\mathbf{0 . 5}^{\circ}$} & \multicolumn{2}{c}{$\mathbf{0 . 6 6}^{\circ}$} & \multicolumn{2}{c}{$\mathbf{1 . 5}^{\circ}$} \\
\cline { 2 - 7 }$m$ & Head & Tail & Head & Tail & Head & Tail \\
\hline 1 & $2.49 \%$ & $2.40 \%$ & $2.45 \%$ & $2.11 \%$ & $3.38 \%$ & $2.96 \%$ \\
2 & $3.59 \%$ & $2.56 \%$ & $2.66 \%$ & $2.34 \%$ & $2.67 \%$ & $2.63 \%$ \\
\hline
\end{tabular}

When $\alpha^{\prime}=0.5^{\circ}$, the S-bending area was so long that the efficiency of the shearer's bevel cutting was very low, and the hydraulic support could not be timely supported. Although the scraper conveyor consumed less current when $\alpha^{\prime}=0.5^{\circ}$, the time for the shearer to cut a knife coal was increased by $20 \%$, and the MTBF was raised by $15 \%$. Therefore, $\alpha^{\prime}=0.5^{\circ}$ was unacceptable. In other words, the mining model with smaller $\alpha^{\prime}$ was not good.

The horizontal bending angle $\alpha^{\prime}$ was changed to $0.66^{\circ}$ and used under the mine for one year. The replacement frequency of the sprocket assembly was reduced by $50 \%$, which saved about $\$ 284,000$. The total electricity consumption of the working face was reduced by $31 \%$, thus $\$ 97,000$ was saved. Due to the decrease of MTBF, production time increased, and 32,000 more tons of coal were produced than the previous year. The correctness and feasibility of the simulation results were verified.

\section{Conclusions and Future Work}

To make the working mode of the coal mining face better, a new method based on the running resistance characteristics and the improved BA is proposed in this paper. Under consideration of the direction of the shearer's running direction, the mathematical model of the running resistance of the scraper conveyor was established. The improved strategy based on adjusting the step size of the search by inertia weight and expanding fly distance range obeying the t-distribution was applied in the optimization process. To verify the feasibility and superiority of MBA, a simulation comparison was made. Finally, the simulation results were applied in the 21220 fully mechanized mining face of Changcun Mine. The conclusions are as follows:

1. The current consumption and running resistance of three different $\alpha^{\prime}$ cases were compared. The results show that the average absolute error rate of theoretical calculation and measured current value was $3 \%$. The correctness of the mathematical model was verified.

2. The improved bat algorithm (MBA) had faster convergence speed and higher accuracy than AMBA, BCBA, and BAO algorithms. MBA was superior in searching for optimal horizontal bending angles.

3. When $\alpha^{\prime}=0.66^{\circ}$ was compared with the usual bending angle, not only the current consumption and the cost per ton of coal were reduced, but the MTBF was reduced by $50 \%$. The correctness and feasibility of the simulation results were verified by industrial application.

In future studies, the authors will focus on improving the proposed approach. This may be done by including unknown factors that affect the operational resistance to be explored and by developing an improved algorithm with higher execution efficiency.

Author Contributions: C.T. and T.L. contributed the new processing method; Z.W. and J.X. designed the simulations and experiments; Y.M. and T.W. performed the experiments; and T.L. wrote the paper.

Acknowledgments: The support of the National Natural Science Foundation of China (No. U1510117), the National Key Basic Research Program of China (No. 2014CB046301) and the Priority Academic Program Development (PAPD) of Jiangsu Higher Education Institutions in carrying out this research are gratefully acknowledged.

Conflicts of Interest: The authors declare no conflict of interest. 


\section{References}

1. Shen, B.H.; Guo, Y.H. Development Status and Tendency of Technology and Equipment for Fully Mechanized Coal Mining in China. Coal Sci. Technol. 2012, 40,1-3.

2. Wang, X.W.; Wang, S.P.; Long, R.S.; Yang, Z.J.; Liu, G.P. Rigid-flexible coupled dynamic contact analysis for a chains drive system of a heavy scraper conveyer during loading start-up. J. Vib. Shock 2016, 35, 34-40.

3. Ordin, A.A.; Metel'Kov, A.A. Analysis of longwall face output in screw-type cutter loader and scraper conveyor system in underground mining of flat-lying coal beds. J. Min. Sci. 2015, 51, 1173-1179. [CrossRef]

4. Zhang, L. Research on Key Technologies of Autonomous Following Mining Machine for Hydraulic Support. Ph.D. Thesis, China University of Mining and Technology, Xuzhou, China, 2017.

5. Crawford, K.S.; Epperly, R.A.; Murphy, H.G.; Saunders, L.A. Applying Adjustable Frequency Controllers to High-Starting-Torque Loads. In Proceedings of the Petroleum and Chemical Industry Conference, St. Louis, MO, USA, 13-15 September 1993; pp. 89-100.

6. Murphy, C.J.; Bliss, R.E. Method and Apparatus for Belt Conveyor Load Tracking. U.S. Patent 5,335,777, 9 August 1994.

7. Dolipski, M.; Remiorz, E.; Sobota, P. Dynamics of Non-Uniformity Loads of AFC Drives. Arch. Min. Sci. 2014, 59, 155-168. [CrossRef]

8. Wang, K. Research on Shearer Speed Control Technology Based on Scraper Conveyor Load Prediction. Master's Thesis, China University of Mining and Technology, Xuzhou, China, 2015.

9. Morley, L.A.; Kohler, J.L.; Smolnikar, H.M. A model for predicting motor load for an armored face-conveyor drive. IEEE Trans. Ind. Technol. 1988, 24, 649-659. [CrossRef]

10. Swider, J.; Herbus, K.; Szewerda, K. Dynamic analysis of scraper conveyor operation with external loads. In Proceedings of the 4th International Conference on Computing and Solutions in Manufacturing Engineering 2016-CoSME'16, Braşov, Romania, 3-4 November 2016; pp. 1-6.

11. Dolipski, M.; Cheluszka, P.; Remiorz, E.; Sobota, P. Follow-Up Chain Tension in an Armoured Face Conveyor/Nadążne Napinanie ańcucha Zgrzebłowego W Przenośniku Ścianowym. Arch. Min. Sci. 2015, 60, 25-38. [CrossRef]

12. Sdvyzhkova, O.; Patyńska, R. Effect of increasing mining rate on longwall coal mining-Western donbass case study. Stud. Geotech. Mech. 2016, 38, 91-98. [CrossRef]

13. Krawczyk, J.; Pawlowski, B. The Analysis of the Tribological Properties of the Armoured Face Conveyor Chain Race. Arch. Min. Sci. 2013, 58, 1251-1262.

14. Broadfoot, A.R.; Betz, R.E. Power requirement prediction for armoured face conveyors. Min. Technol. 2014, 109, 93-101. [CrossRef]

15. Shi, Z.; Zhu, Z. Case study: Wear analysis of the middle plate of a heavy-load scraper conveyor chute under a range of operating conditions. Wear 2017, 380, 36-41. [CrossRef]

16. Liu, K.M. The Mechanical Study of Scraper Conveyor. Master's Thesis, Hebei University of Technology, Tianjin, China, 2005.

17. Jiao, H.Z.; Yang, Z.J.; Wang, S.P. Contact dynamics simulation analysis for sprocket transmission system of scraper conveyor. J. China Coal Soc. 2012, 37, 494-498.

18. Yang, X.S. A New Metaheuristic Bat-Inspired Algorithm. Comput. Knowl. Technol. 2010, 284, 65-74.

19. Yang, X.; Ah, G. Bat algorithm: A novel approach for global engineering optimization. Eng. Comput. 2012, 29, 464-483. [CrossRef]

20. Altringham, J.D.; Mcowat, T.; Hammond, L. Bats: Biology and behaviour. Q. Rev. Biol. 1998, 78, 43-57.

21. Chen, M.; Feng, J.; Li, Z.; Zhou, J.; Zhao, H.; Zhang, S.; Sheng, L. Echolocation sound waves, morphological features and foraging strategies in Hipposideros pratti. Chin. J. Appl. Ecol. 2002, 13, 1629-1632.

22. Heraguemi, K.E.; Kamel, N.; Drias, H. Multi-swarm bat algorithm for association rule mining using multiple cooperative strategies. Appl. Intell. 2016, 45, 1-13. [CrossRef]

23. Hafezi, R.; Shahrabi, J.; Hadavandi, E. A bat-neural network multi-agent system (BNNMAS) for stock price prediction: Case study of DAX stock price. Appl. Soft Comput. J. 2015, 29, 196-210. [CrossRef]

24. Bento, P.M.R.; Pombo, J.A.N.; Calado, M.R.A.; Mariano, S.J.P.S. A bat optimized neural network and wavelet transform approach for short-term price forecasting. Appl. Energy 2018, 210, 88-97. [CrossRef]

25. Furmanik, K.; Pracik, M. Method for evaluation of movement resistance in scraper pipe conveyors. Proc. Appl. Math. Mech. 2010, 7, 4130043-4130044. [CrossRef] 
26. Mao, J.; Cao, H.; Xie, M. Load characteristic analysis and simulation of scraper conveyor under stable operation. J. Liaoning Technol. Univ. 2017, 36, 1298-1302.

27. Nie, R.; He, B.Y.; Yuan, P.; Zhang, L.; Li, G. Novel approach to and implementation of design and analysis of armored face conveyor power train. Sci. China Technol. Sci. 2015, 58, 2153-2168. [CrossRef]

28. Yu, Y.D. Calculation of additional resistance of curved conveyor chain of scraper conveyor. J. Hunan Univ. Sci. Technol. 1995, 2, 38-42.

29. Euler, L. Leonhard Euler and the Koenigsberg Bridges. Sci. Am. 1953, 189, 66-70. [CrossRef]

30. Wang, C.J.; An, J.S.; Wu, X.G.; Liu, D.Y.; Zheng, Y.Z. Research and Application of Tighting Chain Device for 40T Scraper Conveyor. Colliery Mech. Electron. Technol. 2013, 767, 141-147.

31. Xie, J.C.; Yang, Z.J.; Wang, X.W.; Wang, S.P.; Zhang, Q. Cooperative solving method of chute postures in the bending section of a scraper conveyor. Adv. Mech. Eng. 2018, 10, 1687814018767684. [CrossRef]

32. Liao, H.Q.; Qiu, Y.; Yang, X. A Study of Weight Coefficient Method Based on AHP. Mech. Eng. 2012, 6, $22-25$.

33. Goyal, S.; Patterh, M.S. Modified Bat Algorithm for Localization of Wireless Sensor Network. Wirel. Pers. Commun. 2016, 86, 657-670. [CrossRef]

34. Wang, C.F.; Song, W.X.; Liu, L.X. An adaptive bat algorithm with memory for global optimization. IAENG Int. J. Comput. Sci. 2018, 45, 320-327.

35. Wang, Y.P. Research on Key Technology of Scraper Conveyor and Shearer Coordinated Speed Control. Master's Thesis, China University of Mining and Technology, Xuzhou, China, 2016.

(C) 2019 by the authors. Licensee MDPI, Basel, Switzerland. This article is an open access article distributed under the terms and conditions of the Creative Commons Attribution (CC BY) license (http://creativecommons.org/licenses/by/4.0/). 